\title{
O Teatro do Oprimido como instrumento para a educação ambiental
}

\author{
Flávio José Rocha da Silva ${ }^{1}$ \\ Francisco José Pegado Abílio²
}

Resumo: Este artigo é o resultado de uma pesquisa com um grupo de estudantes de uma escola pública no bairro Mutirão da cidade de Bayeux - PB, no segundo semestre de 2008 e no primeiro semestre de 2009. Durante esse período, coordenamos trinta oficinas lúdico-pedagógicas baseadas no Teatro do Oprimido e discutimos temas ligados à questão ambiental. Ao final de cada semestre, o grupo apresentou peças teatrais com as temáticas lixo na escola e degradação do Parque Estadual da Mata do Xem-Xem, localizado no mesmo bairro. Para averiguar o resultado da nossa pesquisa, aplicamos questionários às turmas do $9^{\circ}$ ano do Ensino Fundamental e do $2^{\circ}$ ano do Ensino Médio ao início e ao término do nosso trabalho. Pudemos constatar um crescimento no nível de entendimento da maioria dos educandos das referidas turmas acerca da problemática ambiental, confirmando que o Teatro do Oprimido pode ser utilizado como ferramenta pedagógica para facilitar a educação ambiental.

Palavras-chave: Educação Ambiental. Teatro do Oprimido. Justiça ambiental.

\section{The Theater of the Oppressed as an environmental education tool}

Abstract: This paper is the result of a research with a group of volunteer students from a public school located in the Mutirão neighborhood, city of Bayuex, Paraíba, during the second semester of 2008 and the first semester of 2009. Throughout that time, we coordinated thirty pedagogical and recreational workshops based on the Theater of the Oppressed techniques and discussed themes related to environment. At the end of each semester, the group presented plays based on two themes: garbage on the school grounds and on the devastation of the Xem-Xem Forest State Park, located in the same neighborhood. At the beginning of the research and at the end of the workshops, we administered questionnaires to $9^{\text {th }}$ and $11^{\text {th }}$ grade students to discover if there was an increase in the level of understanding environmental problems. Our research confirms that the Theater of the Oppressed can serve as a pedagogical tool to make environmental education easier.

Keywords: Environmental Education. Theater of the Oppressed. Environmental justice.

\footnotetext{
${ }^{1}$ Doutorando em Ciências Sociais na PUC-SP. flaviojoserocha@gmail.com
}

2 Professor da Universidade Federal da Paraíba. chicopegado@hotmail.com 


\section{Introdução}

A crise ambiental exige novas formas de exercitar a educação no que concerne à busca por alternativas para forjar sujeitos que modifiquem e multipliquem novas práticas comportamentais na relação entre a espécie humana e o meio ambiente (GOLDBERG, 2006; RUSS; ALMEIDA; SAVI, 2009). Um dos caminhos apontados para subverter a ordem cartesiana da educação é a presença das várias formas de expressão artística no processo de aprendizagem. Araújo e Pasquarelli (2007, p. 328) afirmam:

As artes e as religiões desenvolveram caminhos para integrar o ser humano com o cosmos. Cada uma delas em seu contexto cultural e histórico, a seu modo. Nosso papel talvez seja o de resgatar e resignificar esses conhecimentos para nos re-encontrarmos com o mundo e, através da educação, ajudarmos outras pessoas a se reencontrarem.

A arte é uma forte aliada no processo educativo. Para Morais e Sato (2008, p. 2050): “A arte-educação e a educação ambiental por serem muito semelhantes trabalham juntas na transformação do homem, por isso, estão sempre ligadas numa estreita relação, sendo a linguagem artística natural ao desenvolvimento do ser humano". Ela pode estreitar a distância entre os conhecimentos científicos e o cidadão comum e ajudar na sensibilização dos problemas ambientais (GOLDBERG, 2006).

\section{Teatro e educação ambiental}

O nascimento do teatro se dá com a necessidade que o ser humano tem de "ser outro" e representar os deuses ou os animais que iriam ser caçados para a sua sobrevivência (COURTNEY, 2003; PEIXOTO, 1981), o que implica uma relação dessa expressão artística, desde sua criação, com a natureza. Logo, essa afinidade não é algo novo, embora se revista de outros conteúdos em nossos dias.

São muitas as vantagens de se utilizar o teatro como um instrumento na educação ambiental (EA). Uma delas é o exercício lúdico-metodológico e a possibilidade de ter a participação de todos, mesmo daqueles e daquelas que estão presentes no ato apenas como espectadores, pois respondem com emoções como o choro, a risada, as expressões faciais as mais diversas etc. Outra vantagem é expressar o mesmo discurso que seria usado em uma aula expositiva de forma diferente e, assim, possibilitar novas formas de educar. Os jogos teatrais são facilitadores da aprendizagem, como afirma Boal (2003, p. 166):

Esta é a forma mais natural de aprendizagem e a mais arcaica, pois a criança aprende a viver por meio do teatro, brincando, interpretando personagens. Os jogos teatrais sintetizam as antitéticas disciplina e liberdade - todo jogo tem regras claras que devem ser obedecidas; mas, mesmo obedecendo a regras, a 
invenção é livre, a criação necessária, e a inteligência pode e deve ser exercida.

O teatro também tem a vantagem de poder ser adaptado para os diferentes espaços, já que não há a obrigatoriedade de um espetáculo ser exibido em um palco convencional. Sendo assim, basta uma ideia que configure uma história geradora de conflito para se ganhar a atenção do espectador. Boal (1996, p. 83) assim comenta a necessidade do conflito no teatro:

O filósofo Hegel responde: "a essência do teatro é o conflito de vontades livres!” Isto é: um personagem é uma vontade em movimento, uma vontade em busca de sua satisfação, do seu objeto, mas que não obtém de imediato: é o exercício de uma vontade que colide, conflita, com outras vontades, igualmente e opostas.

A arte teatral vem sendo um instrumento eficaz nas diversas tendências da EA em decorrência do uso dos jogos e brincadeiras que podem ser introduzidos com ela, pois na atividade lúdica "o que importa não é apenas o produto da atividade, mas a própria ação, o momento vivido" (ABÍLIO, 2008, p. 344). O teatro como modalidade didática pode contribuir para o processo de reflexão e mudança de postura a ser adotada por integrantes de uma sociedade cada vez mais vítima de um sistema consumista e degradador da vida no planeta.

\section{O Teatro do Oprimido como proposta para uma educação ambiental crítica}

Originalmente antropocêntrico, o Teatro do Oprimido (TO) foi criado para discutir as injustiças sociais. Era um tempo de ditaduras militares na América Latina e as liberdades políticas eram tolhidas dos cidadãos que discordassem desses regimes. Foi nesse ambiente que Augusto Boal começou a fazer uso do teatro para denunciar as opressões contra os trabalhadores e a censura às expressões artísticas.

O debate sobre as questões ambientais estava longe do cotidiano dos brasileiros, mas nos últimos anos o TO tem sido utilizado com uma nova abordagem: a educação ambiental. Embora entendamos que a luta pelos direitos humanos é também uma luta ambiental, pois não somos seres separados da natureza, aqui nos referimos ao contexto de um teatro voltado para os temas que interessam aos seres humanos, mas que não os tem como centro do debate e que aborda as temáticas mais variadas, como lixo, saneamento ambiental, desmatamento, extermínio de animais etc., de forma a expor as inter-relações de todas essas situações e a qualidade de vida dos seres humanos por elas afetados. Para Pereira (2008, p. 79), “o Teatro do Oprimido de Augusto Boal é, no fundo, um feliz encontro entre a política, a educação e a arte”. 
A postura questionadora com relação ao modelo capitalista de sociedade pela qual a EA crítica pretende pautar-se deve seguir um novo caminho ético, principalmente na busca pela superação do antropocentrismo (SILVA; ABÍLIO, 2011). Desse modo: "A educação ambiental vem contribuir em um processo interativo, participativo e crítico para o surgimento de uma nova ética, esta vinculada e condicionada à mudança de valores, atitudes e práticas individuais e coletivas” (GUERRA; ABÍLIO, 2006, p. 33).

Reigota (1994, p. 11) afirma: “A educação ambiental crítica está, dessa forma, impregnada da utopia de mudar radicalmente as relações que conhecemos hoje, sejam elas entre a humanidade, sejam entre esta e a natureza". A EA crítica necessita estar presente no confronto e nos desafios que obstruem o equilíbrio e ameaçam a vida no planeta. Segundo Cardoso (2009), "a educação ambiental entra como subsídio para construir uma consciência ambiental, como também, questionar o modo de como a humanidade vem garantindo a sua existência". Por sua vez, Barcelos (2008, p. 54) nos oferece o seguinte entendimento:

Se existe algum consenso, hoje sobre as questões ambientais e sobre o trabalho com educação ambiental, é que não basta estarmos cientes ou conscientes do que é ou não adequado fazer. Para além disto, é necessário construirmos espaços de convivência em valores tais como a solidariedade, a cooperação, a participação, a responsabilidade, o cuidado, o reconhecimento do outro como legítimo outro na sua diferença. Enfim, mais que "ensinarmos" e/ou transmitirmos conhecimentos e técnicas há que criarmos espaços de exercício de atitudes que sejam mais coerentes com os nossos princípios, fundamentos, teses, teorias, ou pressupostos de mundo, bem como de formas de ser e de estar neste mundo.

Uma grande vantagem na utilização do TO como instrumento pedagógico para a EA é a sua característica de trabalhar com histórias locais sugeridas pelos integrantes dos grupos e poder fazer a relação destas com as escalas regional, nacional e global de modo critico. Além disso, nesse processo os participantes aprenderão a respeitar as diferenças e, consequentemente, valorizarão os interesses da coletividade, e não apenas do indivíduo (LOUREIRO; LIMA, 2006). A prática da ética e do respeito à história local e à ação transformadora está nas raízes do TO, o que demonstra a sua vocação para a pedagogia crítica.

O TO tem sido adotado por vários grupos, dentro e fora do Brasil, como proposta metodológica para a abordagem de temáticas voltadas para a problemática ambiental, sendo a técnica do Teatro Fórum a mais indicada para programas de EA (ALMEIDA, 2004) por atender a um requisito básico para uma EA crítica: a participação ativa. Para Cavalcante (2006, p. 92): “A participação é um princípio no trabalho com a educação ambiental, pois é a partir dela que poderemos avançar nos objetivos de construção de uma sociedade melhor, que pode ser construída nos pequenos espaços e que pode ser vislumbrada a partir de pequenas ações". Ela se dá de maneira cristalizada no TO por possibilitar a liberdade de todos terem o mesmo direito a voz ativa, sugestões e intervenções 
no espetáculo, sempre com a intenção de transformar a realidade dos oprimidos de forma não violenta. Para Pereira (2008, p. 78): “Eis o caráter pedagógico do Teatro do Oprimido muito próximo à filosofia de Paulo Freire 'ninguém educa ninguém, ninguém se educa sozinho, as pessoas se educam entre si, construindo um novo caminho"”.

\section{A experiência com o Teatro do Oprimido como instrumento para a educação ambiental na EEEFMPAG: o cenário, o figurino e os atores}

\section{O cenário}

A Escola Estadual de Ensino Fundamental e Médio Professor Antônio Gomes - EEEFMPAG - foi fundada em 1984 e está localizada no Bairro Mario Andreazza, conhecido como Bairro do Mutirão (BM), município de Bayeux, Paraíba. Foi construída por reivindicação dos moradores daquela comunidade (SILVA, 1984). Esse estabelecimento de ensino recebe diariamente mais de dois mil alunos nos três turnos e é o único a oferecer o Ensino Médio em uma área habitada por mais de dez mil pessoas ${ }^{3}$.

Por não possuir lixeiras nas salas de aula, não ter arborização e ter o seu “jardim” repleto de resíduos jogados durante o intervalo das aulas, mostra que há um descaso por parte do poder público no que concerne às escolas da periferia, fato que resulta em uma falta do sentimento de pertencimento por parte dos usuários desse estabelecimento de ensino. Nesse tocante, é válido destacar o questionamento de Freire (1999, p. 50): “Como cobrar das crianças um mínimo de respeito às carteiras escolares, às mesas, às paredes se o Poder Público revela absoluta desconsideração à coisa pública?". Mesmo com todos os problemas apontados, nós acreditamos no potencial multiplicador para uma EA crítica que a EEEFMPAG possui. Como afirma Sato (2001, p. 27):

A escola não é todo-poderosa, mas articula as relações gerais da sociedade, e isto a torna significativa. Ela é uma "subsidiária" e "tributária" daquela grande reprodução social geral, posto que ela, além de exercer influência na formação dos que a freqüentam, representa uma desqualificação ativa na identidade daqueles que não a freqüentam.

O BM, como praticamente todos os bairros periféricos das grandes cidades brasileiras, passa por sérios problemas com relação aos mais elementares direitos para a obtenção de uma qualidade de vida saudável aos seus moradores. São problemas socioambientais, como a falta de saneamento, irregularidade na coleta do lixo, violência doméstica, desemprego etc. Sua população sofre com a privação de direitos básicos a uma cidadania digna.

\footnotetext{
${ }^{3}$ Fonte: Escritório Regional do Instituto Brasileiro de Geografia e Estatística - IBGE - em João Pessoa.
} 
Mesmo nesse cenário com tantos indicadores negativos já descritos, o BM surpreende por guardar um tesouro natural. Há naquele local uma reserva florestal chamada popularmente de Mata do Xem-Xem, cujo nome oficial é Parque Estadual Mata do Xem-Xem ${ }^{4}$ (PEMX).

Criado pelo Decreto Estadual n. 21262, de 07 de fevereiro de 2000, possui uma área total de 187 hectares. A vegetação de ocorrência, entrecortada pelo riacho denominado de Riacho do Meio, é predominante composta por indivíduos da Mata Atlântica. Localizada na Microrregião de João Pessoa, situa-se próximo ao Aeroporto Castro Pinto, no município de Bayeux, distando apenas 7 quilômetros de João Pessoa. (SUDEMA, 2004, p. 160).

Esse Parque, como tantos outros que estão localizados em áreas urbanas brasileiras, sofre com as ações antrópicas mais diversas. Vítima da desigualdade social brasileira, a população vinda das mais diversas partes do estado da Paraíba e de outros estados aloca-se às suas margens, causando-lhe pressão através da utilização da reserva de mata atlântica brasileira para fins de lazer, criação de animais, retirada de madeira, agricultura, depósito de lixo etc.

Por todos os dados apresentados sobre a situação do bairro e do PEMX, uma ação educativa contínua para a melhora de ambos é urgente. A EEEFMPAG pode e deve ser uma ponte para esse processo. Se "a educação inicial não responde mais as transformações atuais, obrigando-nos a refletir sobre o continuum da educação em formas permanentes de educação continuada, um processo que pode levar a vida inteira e correr o risco de ainda não obter respostas satisfatórias" (SATO, 2001, p. 28), não devemos desistir. Propostas como a utilização do TO como instrumento pedagógico podem ser uma das vias para responder a essa urgência educativa de interação com a nova realidade de um mundo cada vez mais complexo e que necessita de ações urgentes para reverter o quadro socioambiental caótico que estamos presenciando. Para Freire (1999, p. 110), "como experiência especificamente humana, a educação é uma forma de intervenção no mundo".

\section{O figurino - procedimentos metodológicos}

Este estudo tem o perfil de pesquisa fenomenológica, uma vez que trabalha com o universo de crenças, valores, atitudes e fenômenos. Teve a intenção de comprovar a validade do método do TO como instrumento pedagógico para a EA e promovê-la na EEEFMPAG através de dados quantitativos obtidos com questionários aplicados aos educandos da referida escola. A escolha dessa escola

\footnotetext{
4 "Nota linguística: gramaticalmente, o nome da ave que dá nome à mata é xenxém (Dendrocygna bicolor, conhecida também como marreca-caneleira). No entanto, os documentos oficiais referentes ao parque insistem em chamá-la de 'xem-xem' ou, pior ainda, 'xém-xém', contrariando ostensivamente as normas ortográficas" (WIKIPÉDIA). Optamos por reproduzir a grafia dos documentos oficiais.
} 
pública nessa área deveu-se, principalmente, por esta estar localizada a cerca de um quilômetro do PEMX.

Nosso alicerce metodológico esteve centrado na Pesquisa Participante, pois, como explicitado anteriormente sobre as características do TO, cremos ser essa uma metodologia adequada para este tipo de trabalho, já que gera a participação de forma não impositiva. Para Abílio (2008, p. 336): “A pesquisa participante vem sendo valorizada por educadores ambientais que vêem a necessidade de propostas alternativas da sociedade para solucionar os problemas ambientais".

O primeiro passo para a realização da nossa pesquisa foi a aplicação de um questionário pré-teste com perguntas objetivas para sabermos o perfil e o nível de percepção dos educandos das turmas do $8^{\circ}$ ano do Ensino Fundamental e das turmas da $1^{\mathrm{a}}$ série do Ensino Médio sobre o meio em que vivem. Esse procedimento foi realizado tendo por base esta afirmação de Freire (1999, p. 71):

Não é possível respeito aos educandos, à sua dignidade, a seu ser formando-se, à sua identidade fazendo-se, se não se levam em consideração as condições em que eles vêm existindo, se não se reconhece a importância dos "conhecimentos de experiências feitos" com que chegam à escola.

No mesmo instrumento, havia perguntas abertas baseadas nas categorias natureza (TAMAIO, 2002), meio ambiente (SAUVÉ, 1997) e EA (GUERRA; ABÍLIO, 1996). Também aplicamos um questionário à diretoria da escola para tomarmos conhecimento sobre as estruturas física e pedagógica do estabelecimento. Em seguida, formalizamos o convite para as oficinas lúdicopedagógicas com os educandos das referidas turmas.

As primeiras quinze oficinas aconteceram no segundo semestre de 2008 e outras quinze aconteceram no primeiro semestre de 2009 (por isso a mudança de $8^{\circ}$ para $9^{\circ}$ ano e de $1^{a}$ para $2^{a}$ série). Nos encontros, os participantes eram sempre expostos aos jogos e exercícios descritos no livro Jogos para Atores e Não Atores, do teatrólogo Augusto Boal (2005), e, logo após sua prática, discutia-se um tema relacionado à questão ambiental com espaço aberto para o diálogo a todos os participantes. Nem sempre esse diálogo foi frutífero, entre outras coisas, por causa do tempo disponível que tínhamos para as oficinas.

Foi ressaltada por nossa parte, a cada encontro, a importância da multiplicação dos diálogos e conclusões a que chegávamos, após as oficinas, para os amigos na sala de aula, familiares e a comunidade em geral. Os participantes também eram instigados a pensar criticamente sobre cada tema. Para Sato (2002): "Estamos nos acostumando com a beleza do inferno, com o gosto pelo tecnodestruição, pela satisfação com o descartável, pelo gosto do consumo desnecessário, pela sociedade do esbanjamento, pelo espetáculo da combustão". Somente o pensamento crítico poderá reverter essa situação.

Ao final de cada semestre foram apresentados espetáculos teatrais com as temáticas escolhidas pelo próprio grupo. No primeiro semestre, o grupo decidiu discutir a problemática do lixo na escola. A escolha desse tema revela o nível das 
discussões até então, centrando-se nos problemas do mundo escolar. O segundo espetáculo aconteceu no final do primeiro semestre de 2009 e teve como tema a degradação do PEMX. Essa temática já mostra um olhar para fora da unidade educacional e a perspectiva do pertencimento a algo maior do que aquele ambiente de formação educativa.

O encerramento da pesquisa deu-se com a aplicação do questionário pósteste, com as mesmas perguntas abertas sobre natureza, meio ambiente e educação ambiental nas turmas do $9^{\circ}$ ano do Ensino Fundamental e da $2^{\mathrm{a}}$ série do Ensino Médio, como forma de verificarmos se houve a multiplicação das discussões com os outros educandos dessas turmas que não participaram das oficinas e quais as concepções formadas a partir da interação com aqueles que participaram.

\section{As dificuldades para o figurino planejado}

Como em todo e qualquer processo de pesquisa, dificuldades e mudanças alheias ao planejamento inicial estiveram presentes. Obviamente, "um método é um caminho que se faz ao caminhar e não um conjunto de receitas e procedimentos" (MORAIS; SATO, 2008, p. 2052). Sendo assim, aqui transcrevemos os empecilhos que surgiram ao longo deste estudo.

A primeira dificuldade foi encontrar um horário comum em que os educandos voluntários pudessem estar juntos. $\mathrm{Na}$ impossibilidade de ter uma solução adequada para todos, decidiu-se que nos encontraríamos no horário escolar vespertino e que esperaríamos até que todos encerrassem as aulas para então dar início às oficinas. Esse fato gerou outro problema, que era não nos demorarmos muito nas atividades para que eles não chegassem às suas casas ao anoitecer, em vista do medo da violência. Como havia muita ausência dos professores, especialmente no segundo semestre de 2008, foi possível contornar essa dificuldade.

O segundo obstáculo foi encontrar um local adequado para facilitar as oficinas. Sem uma sala própria para a prática das aulas de arte, sempre tínhamos de esperar o término das aulas em alguma sala e remover as cadeiras e as carteiras para conseguir um espaço apropriado para a movimentação exigida pelos jogos e exercícios.

Vencidos esses primeiros obstáculos no primeiro semestre, o segundo nos reservou algumas surpresas. Verificou-se que muitos educandos foram transferidos para outro turno ou para outras escolas. Observou-se uma diminuição no número de alunos, principalmente nas turmas da $2^{\mathrm{a}}$ série do Ensino Médio. Esse fator acarretou a diminuição do número de questionários pós-testes aplicados a essas turmas.

As apresentações teatrais também sofreram com as imprevisibilidades inerentes a qualquer ação humana. Com as paralisações e ameaças de greve por parte dos professores das redes estadual e municipal, a nossa intenção de manter os encontros semanalmente não foi concretizada. 
Além dessas dificuldades, a imprevisibilidade da política brasileira teve o seu papel nesta pesquisa. Com a mudança de governador, o cargo de diretor da escola, que geralmente tem laços político-partidários, também sofreu uma mudança. Para nossa sorte, a nova gestora mostrou-se ainda mais interessada em apoiar a nossa pesquisa.

Com o relato das complicações aqui descritas, queremos evitar o que bem nos alerta Sato (2001, p. 16):

Em diversos trabalhos publicados, apresentados ou informados na área de educação ambiental (EA), percebemos uma tendência de somente considerar os bons resultados, fruto de uma trajetória que parece ter sido traçada linearmente, como se os obstáculos e as dificuldades sentidos no caminhar pudessem cegar o mérito da proposta. Isso tem aumentado o grau de fortalecimento da EA, que aparece como se fosse um campo fácil de ser estudado e viabilizado.

\section{Os atores}

Os participantes das oficinas variaram de idade e de gênero, principalmente no primeiro semestre. A partir de fevereiro de 2009, com a saída gradativa dos educandos da $2^{\mathrm{a}}$ série, o grupo tornou-se mais homogêneo em termos de faixa etária, porém, com uma predominância de participantes do sexo masculino.

Com relação aos educandos entrevistados, o universo pesquisado foi de 67 educandos do $8^{\circ}$ ano para o pré-teste e de 63 educandos do $9^{\circ}$ ano para o pósteste. Já para o pré-teste da $1^{\text {a }}$ série foram respondidos 89 questionários, e 43 educandos da $2^{\mathrm{a}}$ série responderam às perguntas do pós-teste. A diminuição no número de educandos na $2^{a}$ série no pós-teste deveu-se a causas externas e nós acreditamos que esse fator não desqualifica o resultado da pesquisa.

As perguntas realizadas apenas no pré-teste exibem o perfil dos educandos e a percepção que têm da EEEFMPAG e do conteúdo recebido nas aulas. As respostas mostram que a grande maioria $\left(30 \%\right.$ do $8^{\circ}$ ano e $44 \%$ da $1^{\text {a }}$ série) usa o tempo livre praticando esportes, sendo possível comprovar que as artes ainda estão ausentes da vida da maioria. Apenas $7 \%$ dos alunos do $8^{\circ}$ ano e $1 \%$ da $1^{\text {a }}$ série afirmaram que se dedicam a esse tipo de atividade quando não estão na escola. O trabalho, dentro ou fora de casa, ainda é uma questão séria a ser levada em conta entre os jovens e os adolescentes do bairro $\left(19 \%\right.$ do $8^{\circ}$ ano e $15 \%$ da $1^{\mathrm{a}}$ série). Esses últimos dados refletem o que revelam as pesquisas sobre trabalho infantil na Paraíba divulgadas em setembro de 2008, as quais informaram que $13 \%$ das crianças e adolescentes paraibanos de 10 a 14 anos trabalham, o mesmo acontecendo com 31,5\% dos jovens entre 15 e 17 anos (SECOM-PB, 2008). A maioria dos educandos $\left(47 \%\right.$ do $8^{\circ}$ ano e $61 \%$ da $1^{\text {a }}$ série) acha a escola um espaço agradável.

Exatos 20\% em cada grupo gostariam de ter uma escola mais organizada e $25 \%$ do $8^{\circ}$ ano e $16 \%$ da $1^{\text {a }}$ série responderam que o ensino da EEEFMPAG 
deve melhorar quando perguntados sobre a escola ideal. A esse respeito, afirma Zaidan (2006, p. 215) que a escola continua "[...] inibindo ou mutilando o desabrochar de outras dimensões fundamentais [à] inteligência humana”. Isso se dá porque, em muitos aspectos, a escola é reprodutora de um modelo cartesiano e ainda se vincula a um sistema que não questiona o padrão de desenvolvimento atual. Sato (2002, p. 8) questiona: "Estará a escola apta para enfrentar as incertezas, arriscar-se pelo inesperado ou aceitar a diversidade?”. E acrescenta: "A educação em sonho deve invadir a arte, a filosofia, a ciência e a técnica".

Um número significativo de educandos, $17 \%$ no $8^{\circ}$ ano e $14 \%$ na $1^{\text {a }}$ série, respondeu que gostaria que os professores tratassem do tema meio ambiente em sala de aula. Esse número revela que o assunto possivelmente ainda não é tratado de forma sistemática como um conteúdo transversal e muito menos interdisciplinar na EEEFMPAG.

Quando perguntados se a EEEFMPAG promovia eventos esportivos e culturais, mais da metade dos alunos de cada turma $\left(54 \%\right.$ do $8^{\circ}$ ano e $58 \%$ da $1^{\text {a }}$ serie) respondeu que sim. Porém, quando a pergunta foi se participavam dessas atividades, $53 \%$ do $8^{\circ}$ ano e $47 \%$ da $1^{\text {a }}$ série responderam que não participavam. Esse resultado mostra que a escola não está conseguindo trazer a comunidade estudantil para o planejamento dessas atividades e, portanto, os educandos não se sentem promotores das mesmas.

Um dado preocupante é o número de educandos fora da faixa etária ideal para o ano que estão cursando. Por exemplo, no $8^{\circ}$ ano, 12\% tinham 16 anos e 9\% tinham 17 anos ou mais em agosto de 2008, quando foi aplicado o pré-teste. Em junho de 2009, durante a aplicação do pós-teste, 14\% tinham 16 anos e 13\% tinham 17 anos ou mais.

O mesmo fenômeno foi observado com as turmas da $1^{\mathrm{a}}$ série: $10 \%$ tinham 18 anos e 4\% tinham 19 anos ou mais em agosto de 2008. Já quando aplicamos o pós-teste, 14\% tinham 18 anos e 5\% tinham 19 anos ou mais. Esses dados comprovam que ainda falta muito para que os filhos e filhas das classes menos favorecidas consigam terminar o Ensino Médio em uma idade compatível que anteceda a entrada no mercado de trabalho. Segundo dados do Instituto de Pesquisas Aplicadas - IPEA -, apenas 48\% dos jovens entre 15 e 17 anos frequentam o Ensino Médio (VIZIA, 2010).

Os dados sobre gênero não trazem muitas surpresas. A maioria das turmas apresenta um número superior de estudantes do sexo feminino. Os números do pré-teste são de $52 \%$ de alunas para o $8^{\circ}$ ano e de $53 \%$ para a $1^{\text {a }}$ série. No pósteste, $63 \%$ responderam ser do sexo feminino no $9^{\circ}$ ano e na $1^{\text {a }}$ série houve a única inversão, com 56\% afirmando ser do sexo masculino.

\section{Diagnóstico sobre a percepção ambiental e sobre o TO}

Embora tivéssemos uma temática para ser abordada a cada oficina, as discussões não seguiam uma linearidade para não limitar os educandos em suas reflexões dentro do tema proposto. Caso isso acontecesse, na semana seguinte voltávamos ao assunto da oficina passada e registrávamos as indagações, 
questionamentos e conclusões dos educandos na perspectiva de que estes estavam sendo irradiados nas salas de aula e em seus espaços de convivência cotidiana. O resultado dessa irradiação pode ser conferido nos gráficos e análises a seguir. As temáticas escolhidas foram postas de forma a fazer uma ponte com o conteúdo escolar e a realidade dos educandos.

A pergunta sobre como eles veem a natureza foi baseada nas categorias de Tamaio (2002) e nós acrescentamos a categoria Não Sei. São elas: Romântica, Antropocêntrica, Generalizante, Naturalista, Socioambiental e Biocêntrica.

Os educandos do $8^{\circ}$ e $9^{\circ}$ anos diminuíram a sua visão Romântica da natureza (de 25\% para 12\%) e aumentaram a visão Naturalista (de 9\% para $32 \%$ ). Também diminuíram aqueles que responderam Não Sei (de 25\% para $7 \%$ ). Contudo, a visão Antropocêntrica praticamente não variou (de $22 \%$ para $23 \%)$.

Gráfico 1 - Percepção dos educandos dos $8^{\circ}$ (esquerda) e $9^{\circ}$ (direita) anos sobre o conceito de natureza.
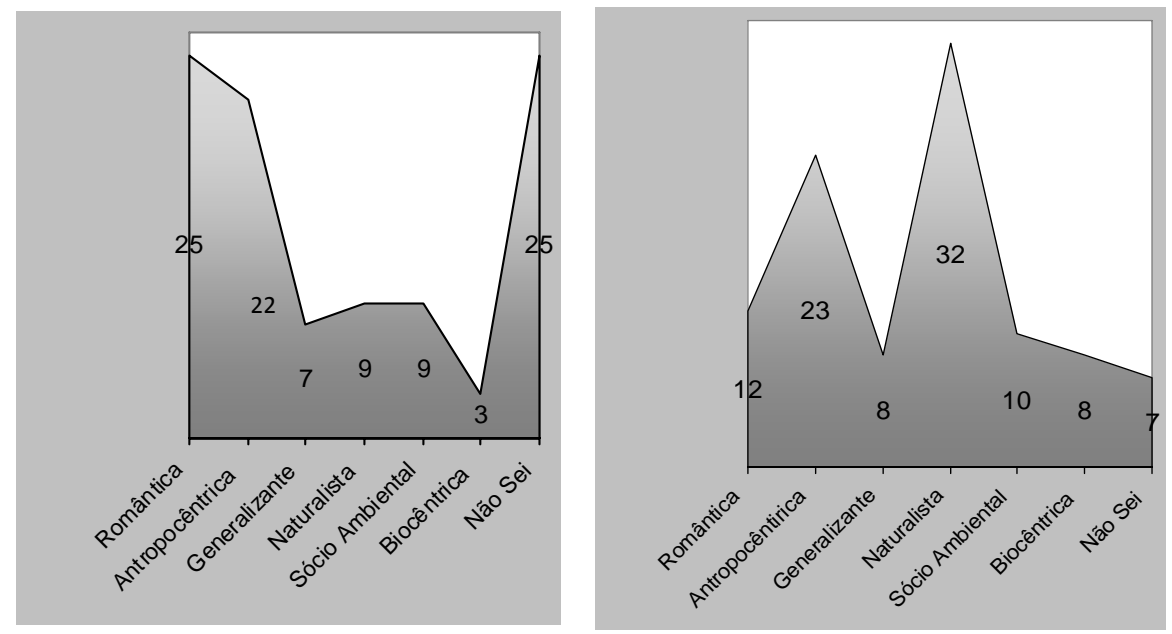

Os educandos da $1^{\mathrm{a}}$ e $2^{\mathrm{a}}$ séries também diminuíram a visão Romântica que tinham da natureza (de 28\% para 11\%) e aumentaram a Socioambiental (de 3\% para 11\%). A visão Antropocêntrica teve uma pequena variação (de 11\% para $13 \%$ ). Para $25 \%$ da $1^{\text {a }}$ série e para $31 \%$ da $2^{a}$ série, ela ainda é vista na categoria Naturalista.

O termo natureza é muito difundido e gera muita confusão, já que é usado popularmente para definir um sem número de fenômenos e acaba se tornando polissêmico. Assim, optamos por distinguir as perguntas sobre natureza e meio ambiente nos questionários pré e pós-testes. 
Gráfico 2 - Percepção dos educandos das $1^{\text {a }}$ (esquerda) e $2^{\text {a }}$ (direita) séries sobre o conceito de natureza.
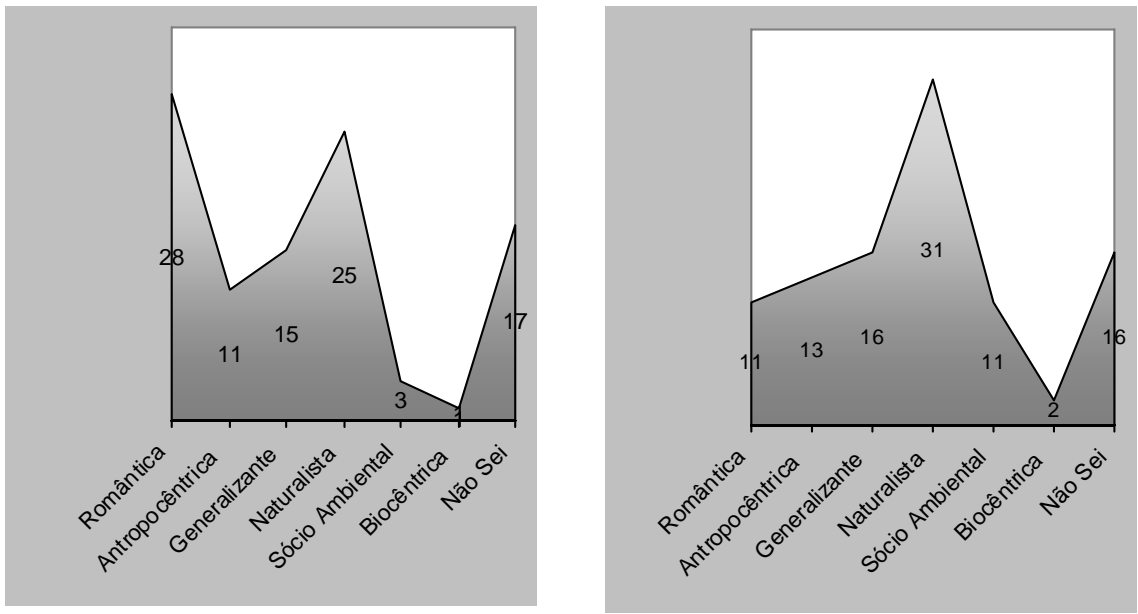

A questão sobre o conceito de Meio Ambiente foi baseada nas categorias de Sauvé (1997) e acrescentamos a categoria Não sei, haja vista o número de educandos que assim responderam. A autora as divide da seguinte maneira: Como natureza, Como recurso, Como problema, Como lugar para viver, Como biosfera, Como Projeto Comunitário. Sauvé (1997, p. 76) afirma: "Essas concepções sobre o meio ambiente podem ser consideradas numa perspectiva sincrônica: elas coexistem e podem ser identificadas nos diferentes discursos e práticas atuais".

O termo meio ambiente é exageradamente usado em nossos dias. A mídia, o governo, as ONGs, as igrejas etc. vêm usando esse termo para qualquer assunto relacionado com ecologia. Sendo assim, é totalmente fácil entender a confusão dos educandos. "O meio ambiente engloba aspectos históricos, culturais, econômicos e sociais, a interação dos seres humanos com os outros seres vivos, de sua espécie ou não, e com os fatores não-vivos, abióticos" (GONÇALVES; SOARES; CORTEZ, 2007, p. 182). As discussões sobre o meio ambiente estão presentes no currículo escolar, mas de forma superficial. Para Sato (2001, p. 19): "A dimensão ambiental é percebida, mas não se inscreve em uma prática pedagógica transformadora".

Do momento da aplicação do pré-teste ao do pós-teste no $8^{\circ}$ e $9^{\circ}$ anos, houve uma diminuição da categoria Não Sei (de 32\% para 22\%) e um aumento das categorias Como Biosfera (de 10\% para 15\%) e Como Lugar para Viver (de 6\% para 16\%). Porém, a categoria Como Problema também teve um aumento (de 9\% para $15 \%)$. 
Gráfico 3 - Percepção dos educandos do $8^{\circ}$ (esquerda) e $9^{\circ}$ (direita) anos sobre o conceito de meio ambiente.
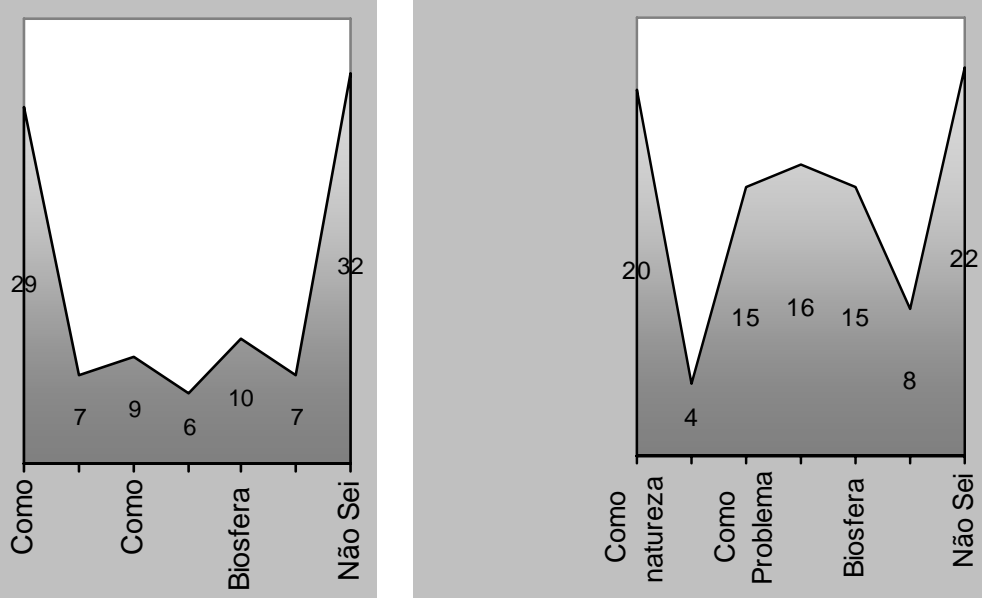

Já na $1^{\mathrm{a}}$ e $2^{\mathrm{a}}$ séries, houve uma mudança significativa de concepção a respeito do meio ambiente. No pré-teste, 24\% responderam Não Sei e no pósteste esse número caiu para 13\%. Na categoria Como Natureza, o número no pré-teste foi de $16 \%$ e aumentou para 35\%. A categoria Como Problema diminuiu de $12 \%$ para $4 \%$ ao final dos dois semestres.

Gráfico 4 - Percepção dos educandos das $1^{\mathrm{a}}$ (esquerda) e $2^{\mathrm{a}}$ (direita) séries sobre o conceito de meio ambiente.
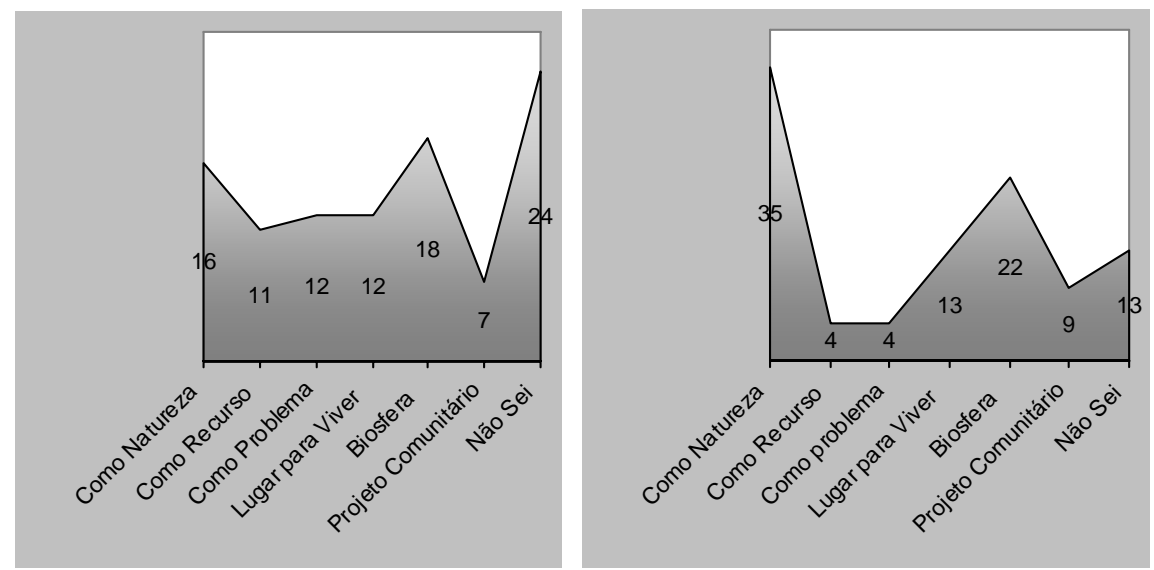

As categorias usadas para a questão sobre o que os educandos entendiam por EA foram criadas por Guerra e Abílio (2006, p. 38). São elas: Generalista, 
Preservacionista, Conservacionista, Sensibilização/Conscientização, Desenvolvimento Sustentável, Ecologista Ecossistêmica e Prática Educativa Socioambiental.

O conceito de EA para os educandos era muito vago quando aplicamos o questionário pré-teste. No $8^{\circ}$ e $9^{\circ}$ anos, 56\% responderam Não Sei no pré-teste e $23 \%$, no pós-teste. A visão Preservacionista não teve variação (14\%) e a Conservacionista variou pouco (de $13 \%$ para $11 \%$ ).

Gráfico 5 - Percepção dos educandos dos $8^{\circ}$ (esquerda) e $9^{\circ}$ (direita) anos sobre o conceito de educação ambiental
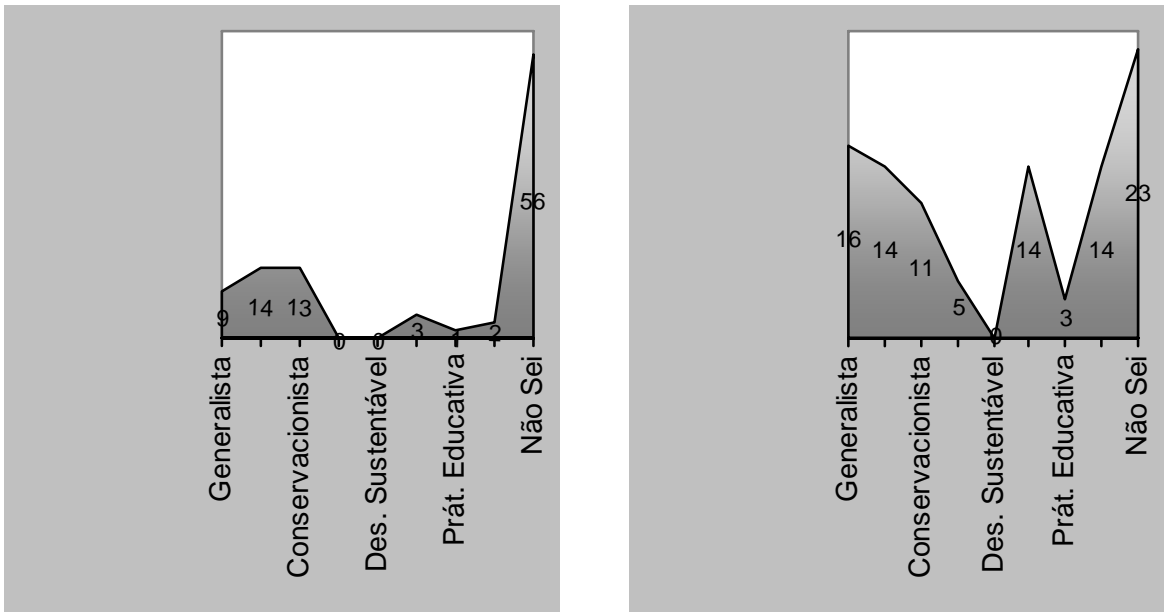

$\mathrm{Na} 1^{\mathrm{a}}$ e $2^{\mathrm{a}}$ séries, o conhecimento sobre EA não era diferente. A resposta Não Sei foi de $43 \%$ no pré-teste e $29 \%$ no pós-teste. A visão Preservacionista não variou (11\%) e a Conservacionista teve um aumento (de 10\% para 16\%). Acreditamos que tal fato se deva a toda a influência exercida pelos meios de comunicação de massa e sua visão acrítica acerca da crise ambiental. 
Gráfico 6 - Percepção dos educandos das $1^{\text {a }}$ (esquerda) e $2^{\mathrm{a}}$ (direita) séries sobre o conceito de educação ambiental.
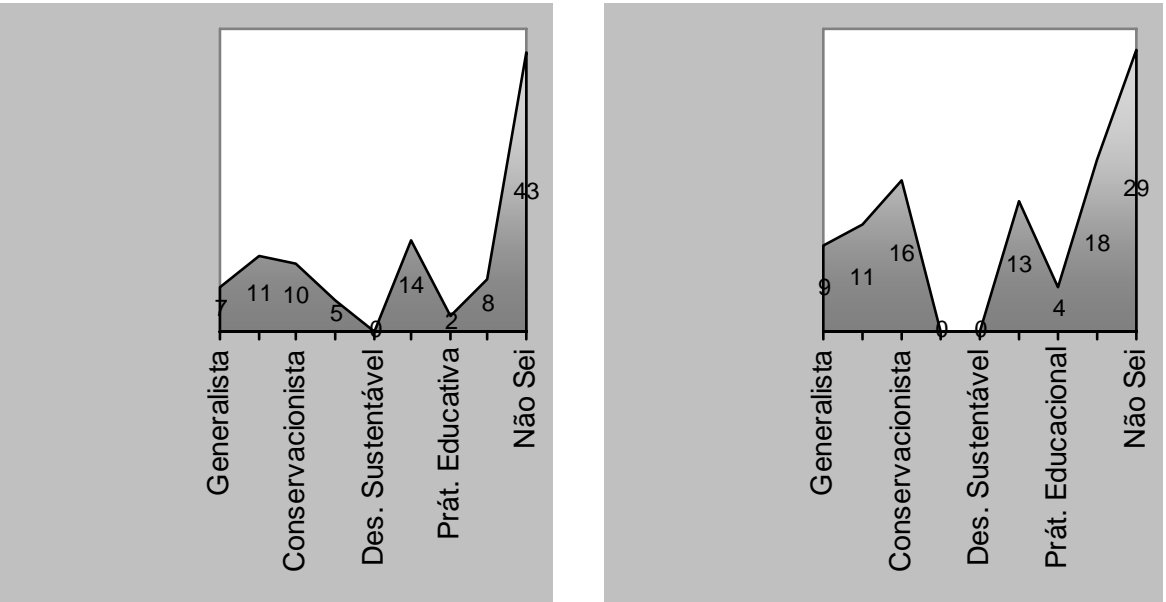

A EA deve penetrar no âmago das questões ambientais, como, por exemplo, o consumismo (GONÇALVES; SOARES; CORTEZ, 2007). Muitas vezes, a EA é vista como uma ação pontual e por isso mesmo não é absorvida pelos educandos.

\section{Considerações}

Nossa experiência na EEEFMPAG demonstrou que o conteúdo repassado de forma mecânica ainda é uma constante na vida escolar da maioria dos educandos desse estabelecimento de ensino público. Nas oficinas semanais nas quais praticamos os jogos e exercícios do TO e fizemos a relação entre esses jogos e o conteúdo sobre meio ambiente, uma atenção especial foi dada à preservação do PEMX. Essa reserva está encravada no meio do BM e vem sofrendo com o crescimento urbano desordenado e suas consequências. Foi possível perceber um aumento no nível das discussões por parte dos integrantes do grupo a cada semana e um aprofundamento das reflexões, como demonstrado nas respostas do pós-teste.

Sem dúvida alguma, a metodologia do TO funcionou como motor para esta experiência como uma EA lúdica, participativa e crítica. Os jogos e exercícios teatrais trouxeram leveza para as discussões e possibilitaram uma abertura e uma cumplicidade que não seria fácil conseguir em tão pouco tempo de encontro e apenas uma vez a cada semana. As discussões relacionadas à temática ambiental, propostas a cada oficina para o acompanhamento dos jogos e exercícios, suscitaram reflexões e questionamentos por parte dos educandos e contribuíram para um embasamento crítico ao atual modelo de desenvolvimento, resultando em concepções diferentes das que os educandos possuíam no início da pesquisa.

Extremamente importante foi a possibilidade de os educandos escolherem as temáticas a serem trabalhadas nos espetáculos teatrais, assim como a confecção 
do cenário para a segunda peça e a composição de uma paródia musical idealizada pelos próprios participantes.

As apresentações também promoveram um importante intercâmbio com os educandos que não fizeram parte do processo semanal das oficinas lúdicopedagógicas.

Uma das surpresas da pesquisa foi a ausência dos educandos da $2^{\mathrm{a}}$ série do Ensino Médio nas últimas oficinas e do processo de produção do segundo espetáculo teatral. Tal fato pode ser atribuído à proximidade de exames para a entrada na universidade e no mundo profissional. Sugerimos que este tipo de trabalho seja desenvolvido com educandos do Ensino Fundamental porque estes ainda não sofrem as pressões para a inserção no mercado de trabalho ou no ensino superior.

Por fim, concluímos que o TO é uma ferramenta válida para a EA e pode ser amplamente utilizada, pois é de fácil acesso e possibilita, além do conhecimento, o prazer de fazer teatro, levar o teatro e deixar que o outro entre, literalmente, no processo e no resultado do espetáculo teatral. Porém, é necessário que o educador ambiental esteja aberto à criatividade dos adolescentes e jovens e seja paciente com as mudanças de humores tão comuns nessa fase da vida.

Acreditamos que esta pesquisa, como todas deveriam, promoveu a justiça e a cidadania ambiental e ajudou um grupo de adolescentes a perceber o mundo à sua volta de uma maneira crítica, mas ao mesmo tempo permeada por arte e novas possibilidades de aprendizagem.

Esperamos que este trabalho tenha contribuído para uma mudança de postura naquela escola e na comunidade onde ela está localizada, pois as grandes mudanças começam com "pequenas peças teatrais". Assim, o PEMX poderá continuar proporcionando o espetáculo da diversidade da vida para todos os que o visitarem.

\section{Referências}

ABÍLIO, Francisco José Pegado. Ética, Cidadania e Educação Ambiental. In: ANDRADE, Maristela Oliveira de (Org.). Meio Ambiente e Desenvolvimento: Bases para uma Formação Interdisciplinar. João Pessoa: Editora Universitária, 2008.

ALMEIDA, Aline Pinto de. Refletindo Sobre Metodologias de Engajamento Comunitário: Teatro do Oprimido como Instrumento para Agenda 21. Revista Brasileira de Educação Ambiental, São Paulo, n. 1, p. 112-115, 2004.

ARAÚJO, Alexandre Falcão de; PASQUARELLI, Vital. Teatro e Educação Ambiental. Um Estudo sobre Ambiente, Expressão Estética e Emancipação. Revista Eletrônica do Mestrado em Educação Ambiental, Rio Grande, v. 18, p. 319-335, jan./jun. 2007.

BARCELOS, Valdo. Educação Ambiental: sobre princípios, metodologias e atitudes. Petrópolis: Vozes, 2008. 
BOAL, Augusto. Teatro Legislativo: Versão Beta. Rio de Janeiro: Civilização Brasileira, 1996.

. O Teatro como Arte Marcial. Rio de Janeiro: Garamond, 2003.

- Jogos para Atores e Não-Atores. Rio de Janeiro: Civilização Brasileira, 2005.

BOFF, Leonardo. Ética da Vida. Rio de Janeiro: Sextante, 2005.

BRASIL. Programa Nacional de Educação Ambiental. Brasília: Ministério da Educação, 2003.

CARDOSO, Claudete da Cruz. Educação Ambiental Crítica: contribuições para uma mente e um sistema sócio-econômico menos degradante. Educação Ambiental em Ação [online], ano VIII, n. 27, 2009. Disponível em: <http://www.revistaea.org/artigo.php? idartigo $=673 \&$ class $=02>$. Acesso em: 20 jan. 2010 .

CAVALCANTE, Ludmila Oliveira Holanda. A Pedagogia radical de Henry Giroux e a Educação Ambiental crítica: rumo a uma ambientalização da pedagogia. João Pessoa: Editora Universitária, 2006.

COURTNEY, Richard. Jogo, Teatro \& Pensamento. São Paulo: Perspectiva, 2003.

FREIRE, Paulo. Pedagogia da Autonomia. Saberes Necessários à Prática Educativa. São Paulo: Paz e Terra, 1999.

GOLDBERG, Luciane Germano. Arte-Educação-Ambiental: o resgate da singularidade e a formação de um imaginário ambiental. In: PAZ, Ronilson José da (Org.). Fundamentos, reflexões e experiências em educação ambiental. João Pessoa: Editora Universitária, 2006. p. 133172.

GONÇALVES, Marcio Luiz Quaranta; SOARES, Maria Lúcia de Amorim; CORTEZ, Ana T. C. Educação Ambiental ou Educação para o Desenvolvimento Sustentável: alternativas para uma crise de civilização. Gaia Scientia, João Pessoa, v. 1, n. 2, p. 181-188, 2007.

GUERRA, Rafael Angel Torquemada; ABÍLIO, Francisco José Pegado. Educação Ambiental na Escola Pública. João Pessoa: Foxgraf, 2006.

GUIMARÃES, Mauro. Educação Ambiental Crítica. In: LAYRARGUES, Philippe Pomier (Coord.). Identidade da Educação Ambiental Brasileira. Brasília: Ministério do Meio Ambiente, 2004. p. 25-34.

LOUREIRO, Carlos Frederico Bernardo; LIMA, Maria Jacqueline Girão Soares de. A Educação Ambiental e a Escola: uma tentativa de (re)concialiação. João Pessoa: Editora Universitária, 2006.

MORAIS, Luciano Ferreira de Morais; SATO, Michèle. O Teatro do Oprimido e da Crueldade como Expressões de Criação Sociopoética e da Educação Ambiental. João Pessoa: Conferência da Terra, 2008.

PEIXOTO, Fernando. O Que é Teatro? São Paulo: Brasiliense, 1981.

PEREIRA, Gladyson S. B. et al. Uma Experiência de Teatro Fórum dentro do MST. Metaxis, n. 5, 2008.

REIGOTA, Marcos. O que é Educação Ambiental. São Paulo: Brasiliense, 1994. 
RUSS, Bruna Ribas; ALMEIDA, Doriane Conceição de; SAVI, Maurício. Sensibilização Ambiental Através da Arte. Educação Ambiental em Ação [online], n. 28, 2009.

SATO, Michèle. Debatendo os Desafios da Educação Ambiental. Revista Eletrônica do Mestrado em Educação Ambiental, Rio Grande, v. 1, p. R14-R33, 2001.

. Educação Ambiental. São Carlos: Rima, 2002.

SAUVÉ, Lucie. Educação Ambiental e Desenvolvimento Sustentável: uma análise complexa. Revista de Educação Pública, v. 6, n. 10, p. 72-102, jul./dez. 1997.

SECRETARIA DE COMUNICAÇÃO DO ESTADO DA PARAÍBA (SECOM-PB). Pesquisa mostra queda do trabalho infantil na Paraíba. Jornal da Paraíba, João Pessoa, 18 set. 2008. Cidades. Disponível em: <http://jornaldaparaiba.com.br/noticia/11973 _pesquisa-mostra-queda-do-trabalho-infantil-na-paraiba>. Acesso em: 20 dez. 2009.

SILVA, Flávio José Rocha da; ABÍLIO, Francisco José Pegado. Por uma Educação Crítica ao Atual Modelo de Desenvolvimento. Revista Eletrônica do PRODEMA, v. 6, n. 1, p. 41-52, mar. 2011.

SILVA, Maria Rizolena Miranda da. História da Fundação do Bairro Mário Andreazza. Bayeux, 1994. Trabalho mimeografado.

SUDEMA. Atualização do Diagnóstico Florestal do Estado da Paraíba 2004. João Pessoa: Gráfica Santa Marta, 2004.

TAMAIO, Irineu. O Professor na Construção do Conceito de Naturez̧a: uma experiência de Educação Ambiental. São Paulo: Annablume, 2002.

VIZIA, Bruno de. Como nossos pais? 28 maio 2010. Disponível em: <http://desafios2. ipea.gov.br/003/00301009.jsp?ttCD_CHAVE=14312>. Acesso em: 30 maio 2010.

WIKIPÉDIA. Unidade de Conservação Estadual da Mata do Xem-xem. Disponível em: <http://pt.wikipedia.org/wiki/Unidade_de_Conserva $\%$ C3\%A7\%C3\%A3o_Estadual_d a_Mata_do_Xem-xem>. Acesso em: 30 jan. 2010.

ZAIDAN, Michel. Políticas Públicas, Escola e Direitos Multiculturais. In: SCOCUGLIA, Afonso Celso; JEZINE, Edineide (Org.). Educação Popular e Movimentos Sociais. João Pessoa: Editora Universitária, 2006.

\section{Artigo recebido em 17/11/2010 e aprovado em 5/07/2011.}

